\title{
Modeling Effects of Outlet Nozzle Geometry on Swirling Flows in Gas Turbine
}

\author{
Hesham Baej*, Adel Akair ,Adel Diyaf, Salem Adeilla, Abdurahman Kraiem \\ Department of mechanical engineering, College of Engineering, Higher institute of science and \\ technology, Gharyan- Libya \\ DOI: https://doi.org/10.21467/proceedings.4.15 \\ * Corresponding author email: heshamttt@gmail.com
}

\begin{abstract}
Swirl stabilised combustion is one of the most successful technologies for flame stabilisation in gas turbine combustors. Lean premixed combustion systems allow the reduction of NOx coupled with fair flame stability. The swirl mechanism produces an aerodynamic region known as central recirculation zone (CRZ) providing a low velocity region where the flame speed matches the flow velocity, thus anchoring the flame whilst serving to recycle heat and active chemical species to the root of the former. Another beneficial feature of the CRZ is the enhancement of the mixing in and around this region. However, the mixing and stabilisation processes inside of this zone have shown to be extremely complex. The level of swirl, burner outlet configuration and combustor expansion are very important variables that define the features of the CRZ. The complex fluid dynamics and lean conditions pose a problem for stabilization of the flame. The problem is even more acute when alternative fuels are used for flexible operation.

Therefore, in this paper swirling flame dynamics are investigated using computational fluid dynamics (CFD) with commercial software (ANSYS). A new generic swirl burner operated under lean-premixed conditions was modelled. A variety of nozzles were analysed using isothermal case to recognize the the behavers of swirl. The investigation was based on recognising the size and strength of the central recirculation zones. The dimensions and turbulence of the Central Recirculation Zone were measured and correlated to previous experiments. The results show how the strength and size of the recirculation zone are highly influenced by both the shear layer surrounding the Central Recirculation Zones (CRZ) and outlet configurations

Keywords: Central Recirculation Zone, swirling flow, CFD, turbulent.
\end{abstract}

\section{Introduction}

A proved technology to reduce the impact of NOx is the use of lean premixing with swirlstabilized combustion. Swirling flow technologies have shown to give high flame stability taking advantage of coherent structures such as corner and central recirculation zones which anchor the flame, recirculating hot products and active chemical species whilst also increasing

(C) 2018 Copyright held by the author(s). Published by AIJR Publisher in Proceedings of First Conference for Engineering Sciences and Technology (CEST-2018), September 25-27, 2018, vol. 2.

This is an open access article under Creative Commons Attribution-NonCommercial 4.0 International (CC BY-NC 4.0) license, which permits any non-commercial use, distribution, adaptation, and reproduction in any medium, as long as the original work is properly cited. ISBN: 978-81-936820-6-7 
their residence time, allowing the use of low equivalence ratios thus giving lower flame temperatures and NOx emissions [1].

However, premixed combustion is not perfect because fuel and air mix just before entering the combustion chamber, thus leading to a significant degree of un-mixedness. These create complex instabilities that would feedback into the mixing-reaction combustion process. Combustion instabilities remain a critical issue limiting the development of low emission, lean premixed gas turbine combustion systems. Strong efforts are currently undertaken for the numerical simulation of swirl-stabilized flames with the intention of designing improved gas turbine combustors [2-3]. The biggest challenge to fuel-flexibility of most combustors is the large differences between natural gas and the proposed replacement fuels. Moreover, gas turbines must meet the current emissions regulations, which often mean running very near lean blowoff. However, blowoff continues to be a phenomenon that is difficult to predict across reactor types and fuel compositions. To describe the lean blowoff behaviour of swirl combustors under various fuel compositions, correlations have to be determined and simplified models developed to allow the implementation of fuel flexible technologies [4].

The crucial feature of swirl burners is the formation of a central recirculation zone (CRZ) which extends blowoff limits by recycling heat and active chemical species to the root of the flame in the burner exit [5-6]. Thus, the CRZ is one of the mechanisms for flame stabilization that through an aerodynamically decelerated region creates a point where the local flame speed and flow velocity match [7]. A vast amount of literature exists on measuring, correlating and predicting blowoff limits for bluff body and swirl stabilized combustors. There are three basic characterizations of the physical phenomena responsible for blowoff. Longwell et al. [8] suggested that blowoff occurs when it is not possible to balance the rate of entrainment of reactants into the recirculation zone, viewed as a well stirred reactor, and the rate of burning of these gases. A different view is that the contact time between the combustible mixture and hot gases in the shear layer must exceed a chemical ignition time. This leads to scaling the characteristic dimension by the recirculation zone length, leading to a similar Da criterion [9]. Current theories are based on a flamelet based description upon local extinction by excessive flame stretch [10]. Flame stretching starts blowoff with the initiation of holes in the flame, that are healed by the same flame creating stretching in areas that otherwise would have been unaffected. Flame will extinguish when flame stretch rate exceeds a critical value. However, it is also recognized that this mechanism is not the one causing the final blowoff, as it is clear from data that the flame can withstand some extinction [11]. Therefore, it is considered that the "critical extinction level" must be somehow influenced by other mechanisms [8-9]. Regarding the central recirculation zone, the use of different configurations has demonstrated that the shape and strength of the CRZ can change drastically depending on these alterations [12-13]. Valera- Medina et al. [13] have observed how the change of the combustor nozzle can produce different central recirculation zones under the same injection conditions.

Proceedings of First Conference for Engineering Sciences and Technology (CEST-2018), vol. 2 
Modeling Effects of Outlet Nozzle Geometry on Swirling Flows in Gas Turbine

\section{Numerical Methodology}

CFD modelling was used to simulate the isothermal of swirl burner. A $100 \mathrm{~kW}$ swirl burner constructed from stainless steel was used to examine the flow behave limits at atmospheric conditions (1 bar, $293 \mathrm{~K}$ ) based to the previous experiments conducted at Cardiff University's Gas Turbine Research Centre (GTRC). Different nozzles were used with various angles: $15^{\circ}$, $25^{\circ}, 35^{\circ}, 45^{\circ}$, with swirl numbers of 1.05 . A single tangential inlet (a) feeds the premixed air and fuel to an outer plenum chamber (b) which uniformly distributes the gas to the slot type radial tangential inlets (c). Swirling unburned fuel then passes into the burner body (d), then into the burner exhaust (e) where the gases pass around the flame stabilizing central recirculation zone. The central diffusion fuel injector $(\mathrm{f}$ ) (which was not used for fuel during the course of this study) extends centrally through the combustor body to the exhaust, Figure1.
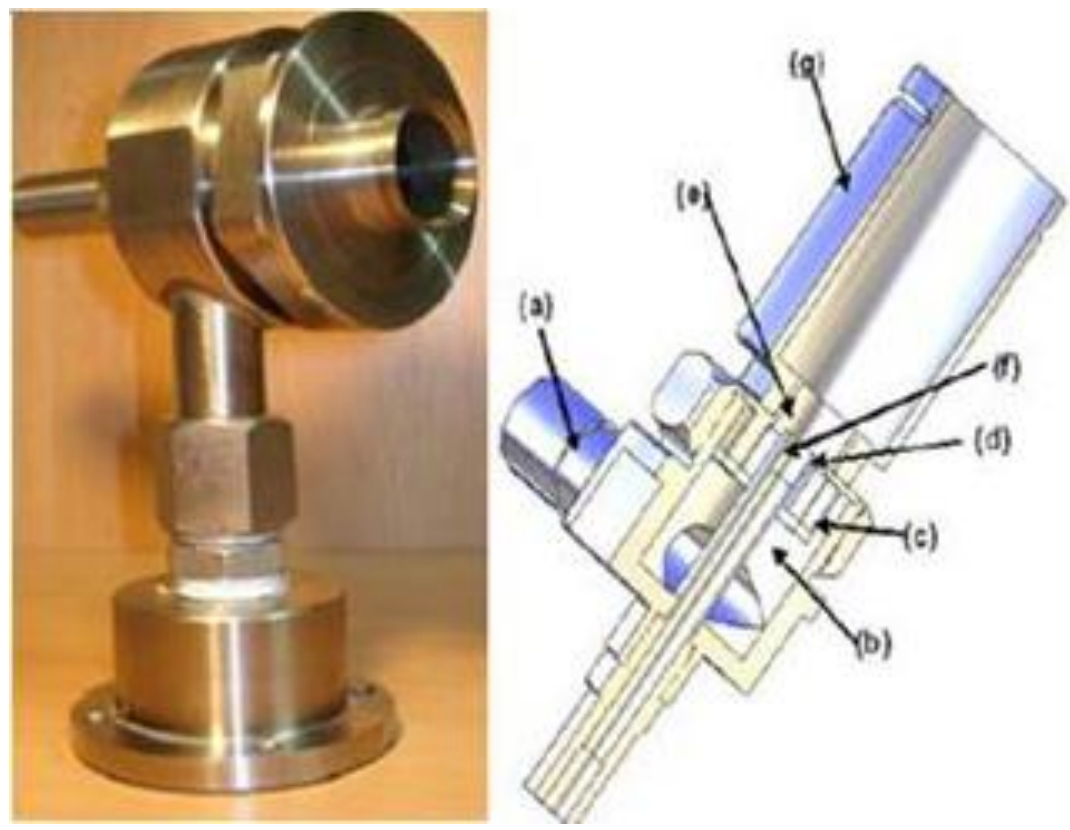

Figure 1: Swirl burner and schematic diagram, respectively.

CFD modelling is initially performed to simulate at the isothermal and atmospheric pressures conditions with $300 \mathrm{~K}$. Isothermal conditions with no combustion were used to calibrate the system and indicate the flow pattern, although it is well known that there are also 3D time, dependant coherent structures, thus the results are of an indicative nature. During the simulation, various types of solvers were investigated and conclusions drawn as to which were the most effective. Based on the experimental results obtained the best turbulent option for the present work was the $x-\omega$ SST model [11,14-16].

Swirl combustor and burners are usually characterized by the degree of swirl, via a swirl number (S). For this particular project, the swirl element of 1.05 has four tangential inlets symmetrically distributed. The swirl burner produces a CRZ that extends back over the central fuel injector, allowing the flame to propagate into this region. This effect can be reduced by 
fitting a divergent of the exhaust nozzle of the burner, as shown in Figure 2, producing a different CRZ.

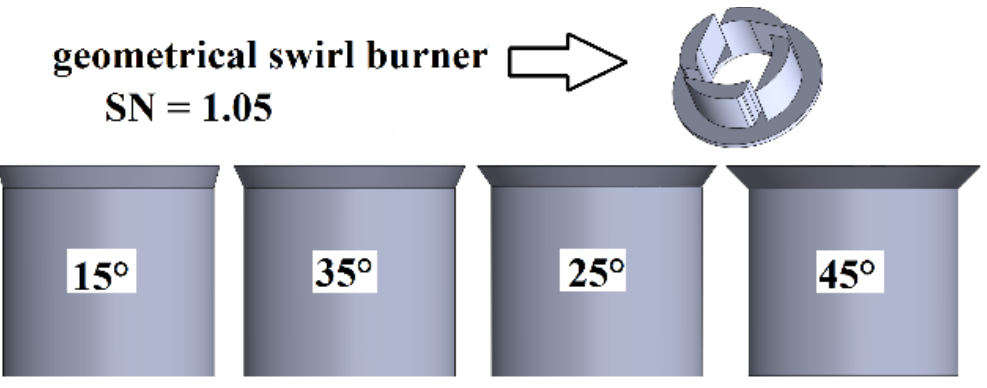

Figuer 2 Geometrical swirl number 1.05 and various divergent angles nozzles, respectively.

\section{Turbulence modelling}

The turbulence model used was the shear-stress transport (SST) k- $\omega$ model, so named because the definition of the turbulent viscosity is modified to account for transport of the principal turbulent shear stress. It has features that give the SST k- $\omega$ model an advantage in terms of performance over both the standard K- $\omega$ model and standard k-e model. Other modifications include the addition of a cross-diffusion term in the $\omega$ equation and a blending function to ensure that the model equations behave appropriately in both the near-wall and far field zones. The turbulence kinetic energy, $\mathrm{k}$, and the specific dissipation rate, $\omega$, are obtained from the following transport equations:

$$
\begin{gathered}
\frac{\partial}{\partial t}(\rho k)+\frac{\partial}{\partial x i}\left(\rho k u_{i}\right)=\frac{\partial}{\partial x_{i}}\left(\Gamma_{k} \frac{\partial}{\partial x_{j}}\right)+G_{k}-Y_{K}+S_{K} \\
\frac{\partial}{\partial t}(\rho \omega)+\frac{\partial}{\partial x_{i}}\left(\rho \omega u_{i}\right)=\frac{\partial}{\partial x_{i}}\left(\Gamma_{\omega} \frac{\partial \omega}{\partial x_{j}}\right)+G_{\omega}-Y_{K \omega}+D_{\omega}+S_{\omega}
\end{gathered}
$$

Calculations for all previous terms have been fully described in [17].

\section{Mesh distribution and Boundary Conditions}

A fresh air at normal conditions was used to simulate the behaviours of the flow pattern based on previous works [18-19]. The air flow mass flow rate and the operating conditions of the burner are given in Table 1 ,

Table 1: Inlet boundary conditions for all nozzles.

\begin{tabular}{|l|l|l|l|}
\hline Test & \multicolumn{1}{|c|}{ Pressure } & Temperature & $\begin{array}{l}\text { Inlet } \\
\text { velocity }\end{array}$ \\
\hline 1 & $1 \mathrm{bar}$ & $300 \mathrm{~K}$ & $2.5 \mathrm{~m} / \mathrm{s}$ \\
\hline 2 & $1 \mathrm{bar}$ & $300 \mathrm{~K}$ & $5 \mathrm{~m} / \mathrm{s}$ \\
\hline
\end{tabular}

FLUENT 15.0 was used to achieve the modelling and simulation [20]. The pre-processor used to construct the model grid was ICEM 15.0The computational mesh consists of 1700162 
Modeling Effects of Outlet Nozzle Geometry on Swirling Flows in Gas Turbine

elements, with a structured grid created with a higher density of nodes in areas where the fluid flow was expected to considerably change and where a finer grid resolution was assumed to be beneficial for achieving an accurate resolution.

This was essentially done close to the burner exit and around the fuel nozzles, Figure 3.

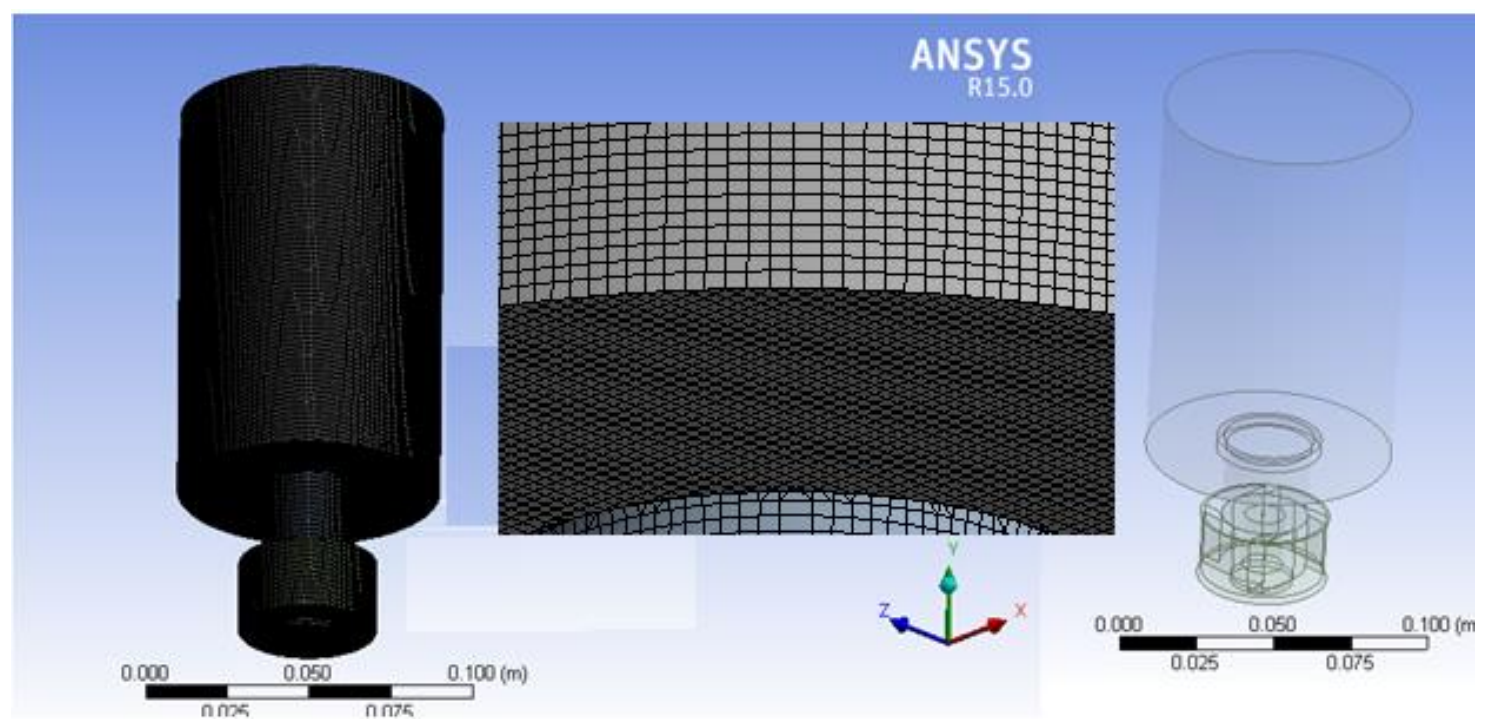

Figure 3. Mesh distribution swirl numbers 1.05 and 1.50, respectively

\section{$5 \quad$ Results and Discussions}

The comparison of the CFD simulation presented in Figure 4(a) and (b) reveals the effects of outlet configurations on the flow pattern. The predicted and measured boundaries of the CRZ for isothermal flows show a longer CRZ extending up to the combustor exit, as expected. However, the usage of different nozzles showed the reduction of both the size and the strength of the CRZ, Table 2.

Table 2. Comparison of isothermal patters of the CRZ using different nozzle angles.

\begin{tabular}{|l|l|l|l|l|l|}
\hline \multicolumn{2}{|l|}{ nlet velocity } & $15^{\circ}$ & $25^{\circ}$ & $35^{\circ}$ & $45^{\circ}$ \\
\hline \multirow{2}{*}{$\begin{array}{l}2.5 \\
\mathrm{~m} / \mathrm{s}\end{array}$} & Width & $1.15 \mathrm{D}$ & $1.20 \mathrm{D}$ & $1.26 \mathrm{D}$ & $1.31 \mathrm{D}$ \\
\cline { 2 - 6 } & length & $2.58 \mathrm{D}$ & $2.60 \mathrm{D}$ & $2.63 \mathrm{D}$ & $2.80 \mathrm{D}$ \\
\hline \multirow{2}{*}{\begin{tabular}{l}
$\mathrm{m} / \mathrm{s}$ \\
\cline { 3 - 6 }
\end{tabular}} & Width & $1.37 \mathrm{D}$ & $1.38 \mathrm{D}$ & $1.40 \mathrm{D}$ & $1.37 \mathrm{D}$ \\
\cline { 2 - 5 } & length & $3.24 \mathrm{D}$ & $3.24 \mathrm{D}$ & $3.29 \mathrm{D}$ & $3.62 \mathrm{D}$ \\
\hline
\end{tabular}

The flow rate increases with the intensity of the shear layer. This will converge into a new structure called High Momentum Flow Region (HMFR), highly correlated to the CRZ [19]. This will increase the strength of the CRZ but reduce its dimensions, as observed in table 2 . The changing of nozzle angles affects the velocity of the flow, thus showing slower profiles than with nozzle $45^{\circ}$. At the same time, it seems that the dimensions of the CRZ with $45^{\circ}$ 
angle have increased to a width of $1.37 \mathrm{D}$ and height of $3.62 \mathrm{D}$, compared to a width of $1.15 \mathrm{D}$ and a height of $2.58 \mathrm{D}$ with nozzles of $15^{\circ}, 45^{\circ}$ under similar conditions, Figure 5. show the progression of the CRZ and its boundaries, defined as a region of greater turbulence compared to the low velocity case. It is clear that the CRZ using high velocity has increased the turbulent intensity with both nozzles $35^{\circ}, 45^{\circ}$ while the observed reduction with the $25^{\circ}$ nozzles at the same conditions as shown in table 3 .

Table 3: Comparison of turbulent intensity of all cases.

\begin{tabular}{|l|l|l|l|l|}
\hline $\begin{array}{c}\text { Turbulent } \\
\text { intenisity }\end{array}$ & $15^{\circ}$ & $25^{\circ}$ & $35^{\circ}$ & $45^{\circ}$ \\
\hline $2.5 \mathrm{~m} / \mathrm{s}$ & $60.3 \%$ & $61.8 \%$ & $63.5 \%$ & $63.8 \%$ \\
\hline $5 \mathrm{~m} / \mathrm{s}$ & $129 \%$ & $66 \%$ & $135 \%$ & $135 \%$ \\
\hline
\end{tabular}
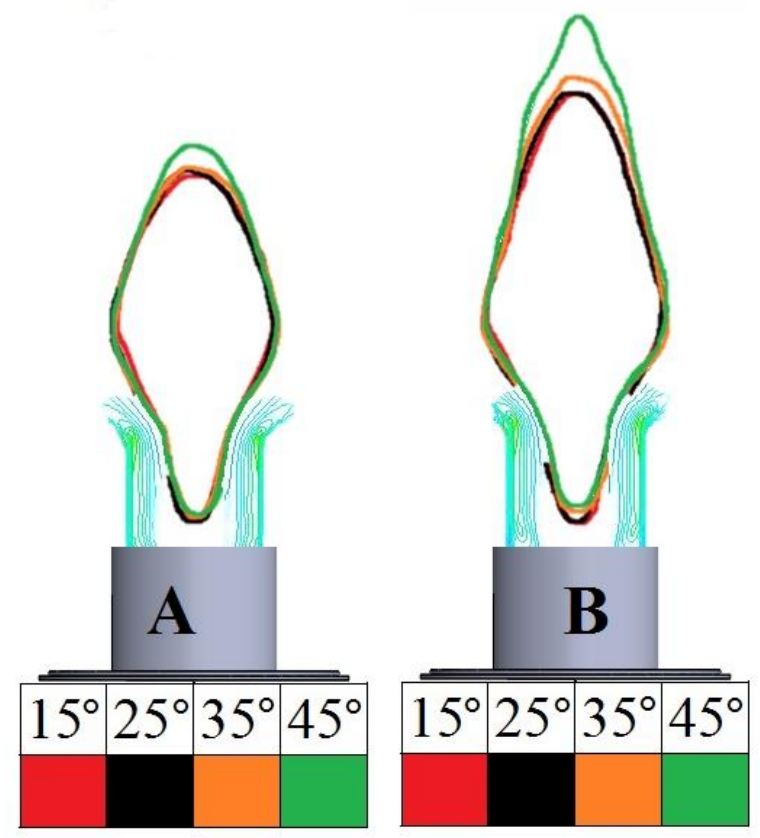

Figure 4. Comparison of CRZ size of all nozzles $A$ at $2.5 \mathrm{~m} / \mathrm{s}$ and $B$ at $5 \mathrm{~m} / \mathrm{s}$

The usage of deferent nozzles alters the size and inner turbulence of the structure; in Table 3 and Figures 5 it is clear that the turbulence intensity inside the CRZ with high velocity blends is higher than with low velocity. The increase of the nozzle divergence from the 15 degree up to 45 degree will increases in almost $7-10 \%$ the turbulence of the structure, whilst augmenting its width and length in $\sim 10 \%$ for all cases, Figure 4 . The length of the recirculation zone increases due to the reduced reaction time of the blend and the higher turbulence inside of the structure.

Proceedings of First Conference for Engineering Sciences and Technology (CEST-2018), vol. 2 


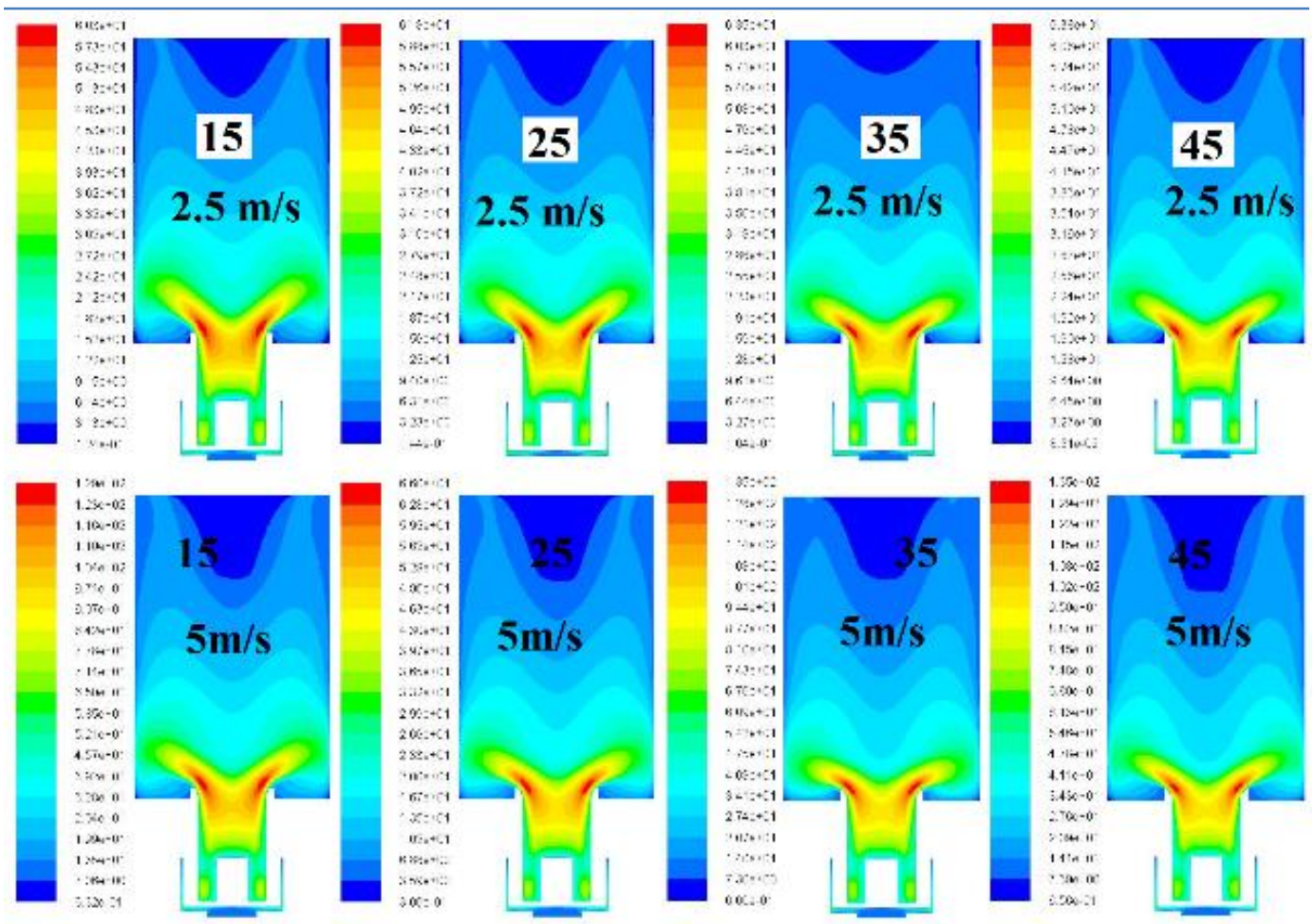

Figure 5 Comparison of turbulence intensity of different velocity $2.5 \mathrm{~m} / \mathrm{s}$ and $5 \mathrm{~m} / \mathrm{s}$.

The flow rate increases with the intensity of the shear layer. This will converge into a new structure called High Momentum Flow Region (HMFR), highly correlated to the CRZ [19]. This will increase the strength of the CRZ but reduce its dimensions, as observed in table 2 . At the same time, it seems that the dimensions of the CRZ with $35^{\circ}$ have increased to a width of $1.40 \mathrm{D}$ and height of $3.29 \mathrm{D}$, compared to a width of $1.37 \mathrm{D}$ and a height of $3.62 \mathrm{D}$ with $45^{\circ}$ nozzle under similar conditions, Figure 4-5. show the progression of the CRZ and its boundaries, defined as a region of greater turbulence compared to the low flow rate.

Figure 6 illustrates the axial velocity using different nozzle angles at a constant mass flow rate. The smallest CRZ width size was observed using the $15^{\circ}$ geometry, as expected. Also the $45^{\circ}$ nozzle produces higher outlet velocities than the $25^{\circ}$ and $35^{\circ}$ divergent angles due to the sharp sudden expansion. The $45^{\circ}$ nozzle generates axial velocities $25 \%$ slower than the straight $15^{\circ}$ geometry, thus allowing a better recuperation of the CRZ. This causes an increase in size of CRZ, Figure 6. 

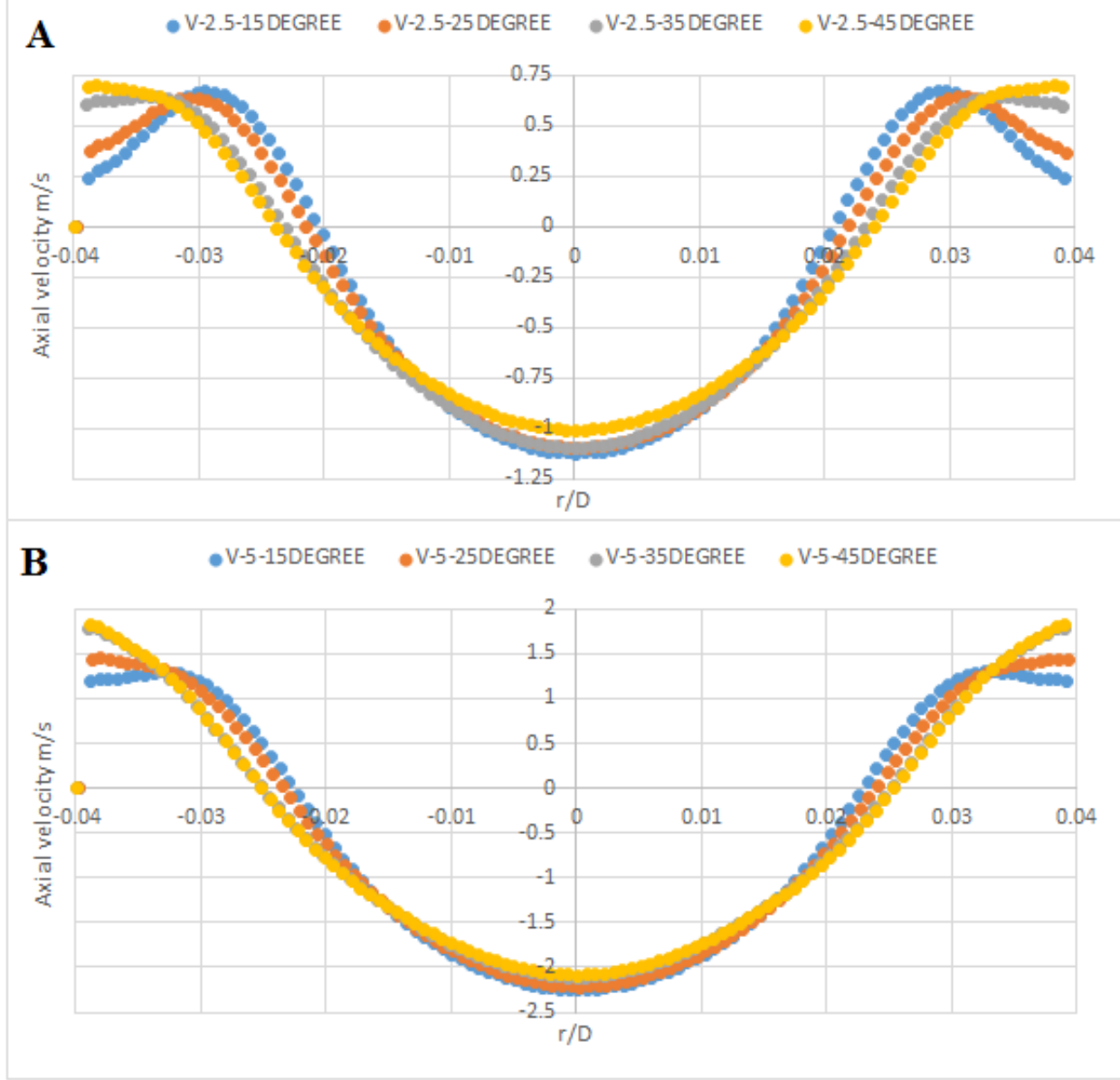

Figure 6 comparison of two velocities A $2.5 \mathrm{~m} / \mathrm{s}$ and $B 5 \mathrm{~m} / \mathrm{s}$

The high momentum shearing flow region illustrated in Figure 7 with swirl numbers of 1.05 shows the divergence of the flow at the outlet of the nozzle. It is clear that the increase in the velocity will produce higher stretch in the radial and tangential direction with a faster decay of velocity in azimuthal direction and wider CRZs. 


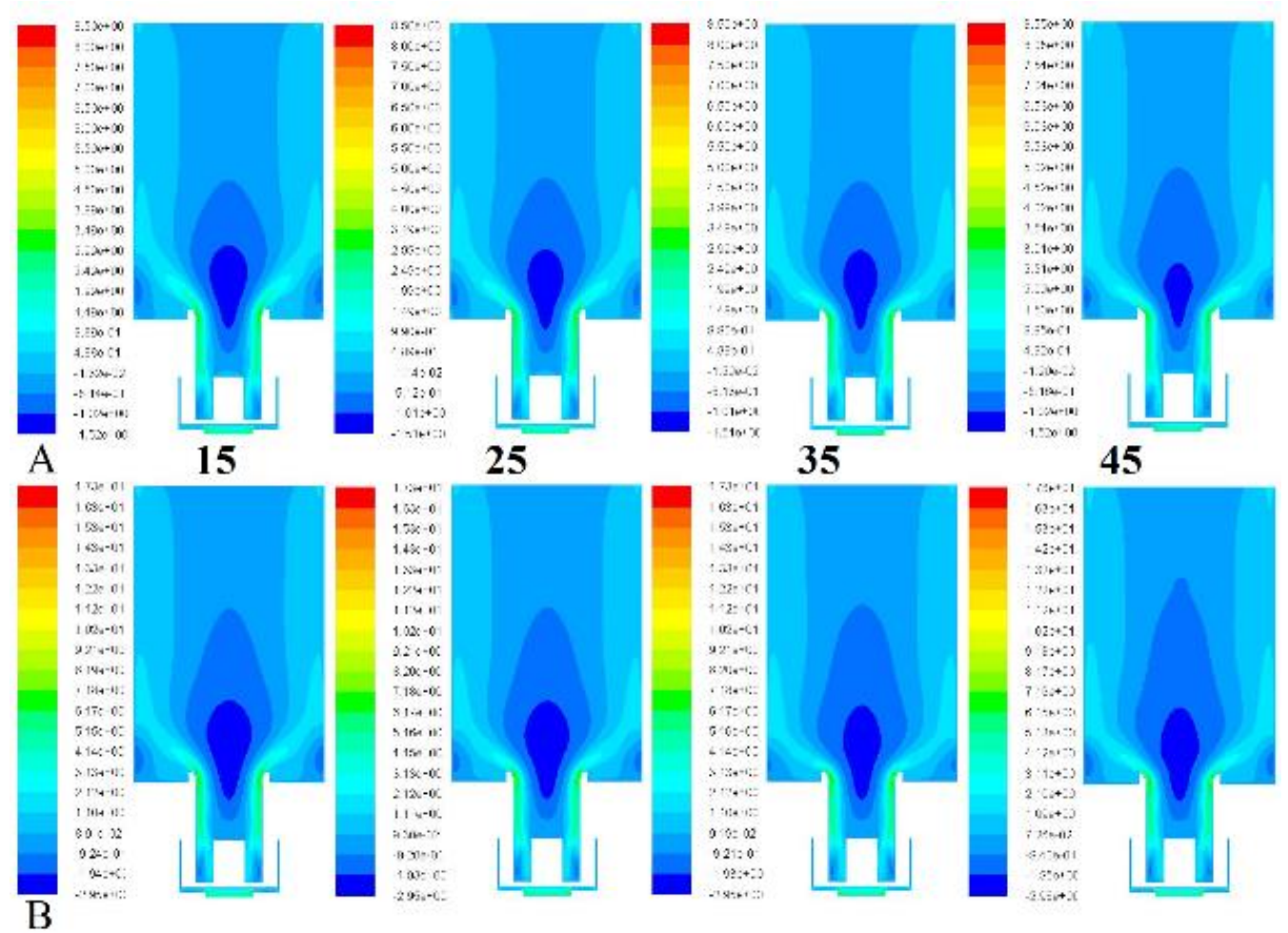

Figure 7 comparison of HMFR using all nozzles

\section{Conclusion}

The CFD predictions of swirl burner aerodynamics show how variable outlet configurations change the CRZ patterns. The changing of the geometry could be have the important factor of great importance to the change of the CRZ. It is clear that the CRZ is increased with the usage of $45^{\circ}$ compared with another outlet nozzles angles. Changing the angle of the nozzle will control the direction of shear layer. This in return could be beneficial for new blends and the increase of the residence time of the products/reactants of the fuels/diluent compositions. The results showed that for all nozzles produced different central recirculation zones under the same power loads. Measurements indicate that the $45^{\circ}$ nozzle produced the largest, and shorter CRZ structure, while the nozzle with the $25^{\circ}$ nozzle produced the narrowest CRZ.

\section{Acknowledgment}

I am gratefully acknowledges the support of the Cardiff university and Libyan Embassy and the Libyan Cultural and Education Bureau in London during my research.

\section{References}

[1]Sadanandan R., Stohr M., Meier W: "Simultaneous OH-PLIF and PIV measurements in a gas Turbine model Combustor”,Applied Physics B, vol. 90, 609-618 (2008). 
[2]Huang, Y., and Yang, V: "Dynamics and stability of lean-premixed swirl stabilized combustion," Progress in Energy and Combustion Science, 35(4), 293-364 (2009).

[3]Syred N,: A review of oscillation mechanisms and the role of the PVC in swirl combustion systems, Prog Energy Combust Sci 32 (2), 93-161(2006).

[4] Megan Karalus: An Investigation of Lean Blowout of Gaseous Fuel Alternatives to Natural Gas, PhD Thesis, University of Washington,(2013).

[5] Lieuwen T, Yang V: Combustion Instabilities in Gas Turbine Engines, Prog. In Astronautics Aeronautics, AIAA, U.S.A., vol. 210, 213-276 (2005).

[6] Tuttle SG, Chaudhuri S, Kotska S, Koop-Vaughan KM, Jensen TR, Cetegen BM, Renfro MW: Time-resolved blowoff transition measurements for two-dimensional bluff body-stabilized flames in vitiated flow. Combust Flame 159, 291305(2012).

[7] Lieuwen T: Unsteady Combustor Physics, Cambridge Press, U.S.A., pp. 430(2012).

[8] Longwell JP, Frost EE, Weiss MA: Flame stability in bluff body recirculation zones. Indust Eng Chem 8, 1629-1633 (1953).

[9] Shanbhogue SJ, Husain S, Lieuwen T: Lean blowoff of bluff body stabilized flames: Scaling and dynamics, Prog Energy Combust Sci, 35, 98-120 (2009).

[10]Driscoll J: Turbulent premixed combustion: flamelet structure and its effect on turbulent burning velocities, Progress in Energy and Combustion Science 34 (1), 91-134(2008).

[11] Poinsot T, Veynante D: Theoretical and Numerical Combustion, R.T. Edwards, U.S.A., pp. 522(2005).

[12]Valera-Medina A, Syred N, Bowen P :Central Recirculation Zone Analysis using a Confined Swirl Burner for Terrestrial Energy, J AIAA Propulsion and Power 29 (1), 195-204 (2013).

[13]Valera-Medina A, Syred N, Griffiths A Visualization of Coherent Structures in a Swirl Burner under Isothermal Conditions. Combustion and Flame 159,1723-1734 (2009).

[14] Versteeg HK and Malalasekera W, An Introduction to Computational Fluid Dynamics - The Finite Volume Method, Longman Group Ltd (1995).

[15] Date A W: Introduction to Computational Fluid Dynamics, Cambridge University Press (2005).

[16] Syred, N.J M.Beer: Combustion in swirling flows: A review combustion and flame 23,143-201(1974)

[17] ANSYS FLUENT 12.0 Theory Guide 2009 [Online]. Available:at www.scribd.com/doc/191713736/Ansys-Fluent-12-0Theory-Guidem

[18] Baej H., Valera-Medina A., Bowen P., Syred N., O’Doherty T., Marsh R ., Impacts on Blowoff by a variety of CRZs using various gases for Gas Turbines

[19] Vigueras-Zuniga MO, Valera-Medina A, Syred N, Bowen P: High Momentum Flow Region and Central Recirculation Zone Interaction in Swirling Flows, SOMIM. Approved

[20] Zimont V, Gas Premixed Combustion at High Turbulence. Turbulent Flame Closure Model Combustion Model. Exp Thermal Fluid Sci 21:179- 186 (2000). 